\title{
The Analysis of Indicators of Information Illumination of Capital Cities in Mass Media as a Factor of their Appeal
}

\author{
Glebova I.S. ${ }^{a}$ \\ Mirsaitova A.A.b \\ ab Kazan Federal University, Institute of Management, Economics and Finance, Kazan, 420008, Russia
}

Doi:10.5901/mjss.2015.v6n1s3p289

\begin{abstract}
Article is devoted to processes of management of a brand of the million-plus cities of Russia on the basis of the analysis of indicators of popularity of the cities for increase of their popularity. The analysis of positioning of the cities by external mass media in comparison to perception of the city it consumers is carried out. As a result of the analysis conclusions are drawn on success of a municipal government in different spheres of development of each million-plus city of Russia and recommendations about elimination of their weaknesses are made.
\end{abstract}

Keywords: city, branding, mass media, appeal of the territory, image of the territory, information illumination.

\section{Introduction}

The qualitative, well-founded brand always has essential impact on social, economic and cultural processes. Branding measures these features, estimating their strong and weaknesses, attractive characteristics.

Branding of the territory is the modern instrument of attraction of attention to it. The increasing competition between the cities forces the city authorities to increase efficiency of the held events for management of a city brand. Also search of a method of an assessment of a brand of the city as way of determination of efficiency of the carried-out branding is actual.

Now everything becomes more noticeable the competition especially between capital million-plus cities which compete in strengthening and development of the communications with bodies of the federal authority, in increase of appeal of the territory to business, involvement of tourists, investors, and also in creation of comfortable conditions for activity directly of residents of the capitals. Understanding by the city authorities of need of maintenance of constantly growing standard of living, and also popularity and popularity of the territory pushes them to carrying out not only competent active social and economic policy in the city, but also to activization of the thought-over communicative work demonstration of hospitality, openness of the territory, its readiness for dialogue and cooperation.

Problems of development of marketing of the territory become more and more actual and are investigated by many foreign and Russian scientists. Theoretical and practical bases of branding of territories are studied by Min K.S., Martin D., Jung J.M. [7], Bagautdinova N., Gafurov I., Kalenskaya N., Novenkova A. [1], which are concentrated on search and justification of use of marketing approach to advance of the territory, formation of its branding and increase of popularity and appeal of the territory, development of its human resources. Batista e Silva J., da GraçaSaraiva M., Loupa Ramos I., Bernardo F. [2] investigate processes of management of branding of the territory, its specifics, influence of a brand of the territory not only on tourists, but also on appeal of goods and services of local producers. Montanari $F$., Scapolan A., Codeluppi E. [8] in the article "Identity and social media in an art festival" place emphasis on the importance of carrying out cultural actions for development of image of the territory. Need of correct positioning of this or that event emphasizes Robinson S. [10]

The cities as object of studying act in works of Heritage Z.a, Green G.bg. [4] Kashnitsky I. [6] in the work "Migration of youths in Russia: Impact on sex-age structures" considers development of appeal of the city to youth which will lead to increase in a young intellectual and working resource. Sepe M., Pitt M. [11], Rakhmangulov A.N., Kopylova O.A. [9], Hu R., Blakely E.J., Zhou Y. [5] in the works pay attention to the social and economic capacity of the territory, comfort of residence of the population in this or that city. Value of investment appeal of the territory was considered by such authors as Blanc-Brude F., Cookson G., Piesse J., Strange R. [3] Thus, it is obvious that the overall objective of development of the territory consists in growth of welfare of residents of the territory taking into account preservation of social and 
economic and ecological balance.

\section{Method}

For an assessment of efficiency of the carried-out branding of the city, for the analysis of the indicators influencing all components of branding it is necessary to choose an effective technique. The carried-out content analysis is based on a communicative component of branding of the city, namely on an assessment of popularity of the city and as this popularity of the city in environment is combined with its popularity among internal consumers. For the analysis the citiesmilionniki of Russia are chosen.

The Russian million-plus cities develop everyone in the way, at each of them the features of management and development, the problems and strengths, the experience. Popularity of any city depends on a set of factors, existence or which absence allows to estimate popularity of the city on different aspects.

For carrying out an assessment of popularity of the city 10 Russian million-plus cities (Novosibirsk, Yekaterinburg, Nizhny Novgorod, Samara, Omsk, Kazan, Chelyabinsk, Rostov-on-Don, Ufa and Volgograd) are investigated. Moscow and St. Petersburg aren't included into the list of the analyzed cities in connection with their special status of the cities of federal value and the world cities, and also in connection with features of their economic development.

For a full-fledged assessment of a communicative component of branding of the city 2 main directions of the analysis are chosen:

1) frequency of illumination of information on the city in federal print media on the main aspects of management of the territory;

2) interest of consumers of Internet resources in information search about the city in concrete aspect of management of the city.

For the content analysis 4 most popular federal newspapers among reader's audience were chosen: Russian newspaper, Independent newspaper, Kommersant, News. The analysis of illumination of each city was carried out on 8 main aspects (for 2012): policy, economy and municipal economy, culture, religion, sport, social sphere, incidents and lawsuits, science. For receiving indicators of interest of consumers of Internet resources in information search about the city in concrete aspect of management of the city it was used a scale of quantity of search queries on the Yandex.ru portal, considered in the territory of Russia. Comparing the received ratings of the cities, it is possible to estimate popularity of the city at mass media, and also among consumers of information, to analyse complexity of process of branding of the cities and to develop effective measures for increase of their popularity.

\section{Results}

On the basis of the obtained data on information popularity of the cities it is possible to draw conclusions on success of a municipal government in different spheres of development of each million-plus city of Russia.

Table 1. Totals of illumination of million-plus cities in federal newspapers for 2012 (quantity of lines)

\begin{tabular}{|c|c|c|c|c|c|c|c|c|c|c|}
\hline Subject & 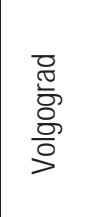 & 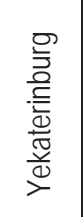 & 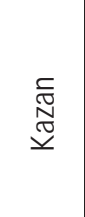 & 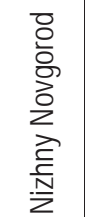 & 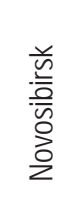 & 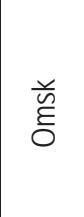 & 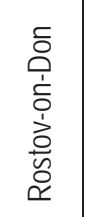 & 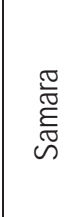 & $\frac{\pi}{5}$ & 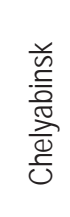 \\
\hline Policy & 1900 & 1057 & 2067 & 1192 & 1217 & 1868 & 637 & 345 & 834 & 1496 \\
\hline Rating & 2 & 7 & 1 & 6 & 5 & 3 & 9 & 10 & 8 & 4 \\
\hline Economy and municipal economy & 2411 & 1376 & 1947 & 1535 & 1288 & 2063 & 1969 & 2621 & 1075 & 1629 \\
\hline Rating & 2 & 8 & 5 & 7 & 9 & 3 & 4 & 1 & 10 & 6 \\
\hline Culture & 1678 & 1011 & 1238 & 892 & 527 & 965 & 219 & 259 & 56 & 107 \\
\hline Rating & 1 & 3 & 2 & 5 & 6 & 4 & 8 & 7 & 10 & 9 \\
\hline Religion & 129 & 83 & 1296 & 34 & 0 & 0 & 0 & 0 & 0 & 65 \\
\hline Rating & 2 & 3 & 1 & 5 & 8 & 8 & 8 & 8 & 8 & 4 \\
\hline Sport & 1537 & 922 & 4879 & 908 & 986 & 2343 & 682 & 722 & 636 & 1329 \\
\hline Rating & 3 & 6 & 1 & 7 & 5 & 2 & 9 & 8 & 10 & 4 \\
\hline Social sphere & 1782 & 962 & 846 & 770 & 1236 & \begin{tabular}{|l}
1272 \\
\end{tabular} & 1152 & 746 & \begin{tabular}{|l|}
645 \\
\end{tabular} & 514 \\
\hline
\end{tabular}




\begin{tabular}{|c|c|c|c|c|c|c|c|c|c|c|}
\hline Rating & $\mathbf{1}$ & $\mathbf{5}$ & $\mathbf{6}$ & $\mathbf{7}$ & $\mathbf{3}$ & $\mathbf{2}$ & $\mathbf{4}$ & $\mathbf{8}$ & $\mathbf{9}$ & $\mathbf{1 0}$ \\
\hline Incidents, lawsuits & 3301 & 3143 & 6505 & 1088 & 3340 & 3262 & 3551 & 3411 & 1221 & 2334 \\
\hline Rating & $\mathbf{5}$ & $\mathbf{7}$ & $\mathbf{1}$ & $\mathbf{1 0}$ & $\mathbf{4}$ & $\mathbf{5}$ & $\mathbf{2}$ & $\mathbf{3}$ & $\mathbf{9}$ & $\mathbf{8}$ \\
\hline Science & 0 & 200 & 583 & 170 & 86 & 953 & 678 & 47 & 48 & 452 \\
\hline Rating & $\mathbf{1 0}$ & $\mathbf{5}$ & $\mathbf{3}$ & $\mathbf{6}$ & $\mathbf{7}$ & $\mathbf{1}$ & $\mathbf{2}$ & $\mathbf{9}$ & $\mathbf{8}$ & $\mathbf{4}$ \\
\hline Total point & $\mathbf{2 6}$ & $\mathbf{4 4}$ & $\mathbf{2 0}$ & $\mathbf{5 2}$ & $\mathbf{4 7}$ & $\mathbf{2 9}$ & $\mathbf{4 6}$ & $\mathbf{5 4}$ & $\mathbf{7 2}$ & $\mathbf{4 9}$ \\
\hline Total rating & $\underline{\mathbf{2}}$ & $\underline{\mathbf{4}}$ & $\underline{\mathbf{1}}$ & $\underline{\mathbf{8}}$ & $\underline{\mathbf{6}}$ & $\underline{\mathbf{a}}$ & $\underline{\mathbf{5}}$ & $\underline{\mathbf{9}}$ & $\underline{\mathbf{1 0}}$ & $\underline{\mathbf{7}}$ \\
\hline
\end{tabular}

Analyzing data from the above-stated table we can draw a conclusion that such cities as Kazan (1 place), Volgograd (the 2nd place) and Omsk (the 3rd place) are leaders in amount of information in federal printing editions. It should be noted that Kazan in 2012 was the absolute leader in illumination by those of policy, religions, sport, and also incidents and lawsuits. Volgograd is in the lead on illumination of subjects of the social sphere and culture. Omsk won first place on illumination of scientific subjects in federal newspapers. Least of all information in 2012 meets about Samara (the 9th place) and about Ufa (the 10th place).

Practically in all considered cities one of the highest rates are indicators on aspect "incidents and lawsuits". It can be explained to that journalists always hunt for scandals and incidents, after all similar headings attract more and more readers. Therefore similar sensational cases long time don't descend from the front pages of newspapers and are discussed still long time.

Table 2. Search queries on the Yandex.ru portal in 2012 on million-plus cities (amount of inquiries)

\begin{tabular}{|c|c|c|c|c|c|c|c|c|c|c|}
\hline Subject & $\begin{array}{l}\frac{\overline{0}}{5} \\
\frac{\overline{0}}{\circ} \\
\frac{0}{\circ}\end{array}$ & 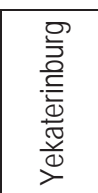 & $\begin{array}{l}\text { ్ָ } \\
\text { ్ָ } \\
\text {. }\end{array}$ & $\begin{array}{l}\text { ते } \\
\text { 产 } \\
\frac{\mathrm{D}}{2} \\
\frac{0}{2} \\
\end{array}$ & 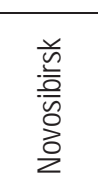 & 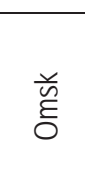 & 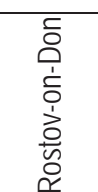 & 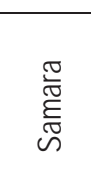 & $\frac{\pi}{5}$ & 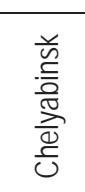 \\
\hline Policy & 9427 & 8188 & 1257 & 6122 & 1053 & 6611 & 1810 & 4156 & 6690 & 2680 \\
\hline Rating & 1 & 2 & 9 & 5 & 10 & 4 & 8 & 6 & 3 & 7 \\
\hline Economy and municipal economy & 6077 & 14811 & 17062 & 44609 & 9157 & 5610 & 5608 & 5464 & 8050 & 10096 \\
\hline Rating & 7 & 3 & 2 & 1 & 5 & 8 & 9 & 10 & 6 & 4 \\
\hline Culture & 19929 & 39184 & 20770 & 23009 & 24774 & 20880 & 14630 & 22757 & 18006 & 24488 \\
\hline Rating & 8 & 1 & 7 & 4 & 2 & 6 & 10 & 5 & 9 & 3 \\
\hline Religion & 0 & 0 & 7451 & 176 & 47 & 93 & 0 & 107 & 401 & 0 \\
\hline Rating & 8,5 & 8,5 & 1 & 3 & 6 & 5 & 8,5 & 4 & 2 & 8,5 \\
\hline Sport & 67221 & 29014 & 71551 & 42980 & 58956 & 11607 & 43046 & 69792 & 61626 & 19449 \\
\hline Rating & 3 & 8 & 1 & 7 & 5 & 10 & 6 & 2 & 4 & 9 \\
\hline Social sphere & 197 & 542 & 0 & 445 & 628 & 170 & 0 & 0 & 0 & 0 \\
\hline Rating & 4 & 2 & 8 & 3 & 1 & 5 & 8 & 8 & 8 & 8 \\
\hline Incidents, lawsuits & 46985 & 24056 & 29611 & 23160 & 22556 & 24469 & 23537 & 32740 & 25450 & 17647 \\
\hline Rating & 1 & 6 & 3 & 8 & 9 & 5 & 7 & 2 & 4 & 10 \\
\hline Science & 743 & 10464 & 7843 & 0 & 19656 & 158 & 26299 & 31504 & 1890 & 2050 \\
\hline Rating & 8 & 4 & 5 & 10 & 3 & 9 & 2 & 1 & 7 & 6 \\
\hline Total point & 40,5 & 34,5 & 36 & 41 & 41 & 52 & 58,5 & 38 & 43 & 55,5 \\
\hline Total rating & 4 & 1 & 2 & 5,5 & 5,5 & 8 & 10 & $\underline{3}$ & 7 & 9 \\
\hline
\end{tabular}

The rating given in table 2 shows how often users the Internet request information on this or that million-plus city of Russia. Having analysed amount of requests on various categories for the cities, the rating in which the leading cities became Yekaterinburg (1 place), Kazan (the 2nd place) and Samara (the 3rd place) was received. The most popular inquiries in 2012 in Internet resources are requests for a sport subject (71 551 inquiries), "incidents and lawsuits" (46 985 inquiries), and also requests for economic subjects (44 609 inquiries).

Least of all the population is interested in questions of the social sphere: the greatest number of inquiries on this subject in Yekaterinburg, but this number makes only 628 inquiries a year. Also people practically don't request information on subjects of religions, except for the city of Kazan (7 451 inquiries). We can explain it to that Kazan is the capital of the Republic of Tatarstan where representatives of 115 nationalities live.

Chelyabinsk and Rostov-on-Don appeared the last in this rating. Their information activity it appeared the lowest for the analyzed period. 


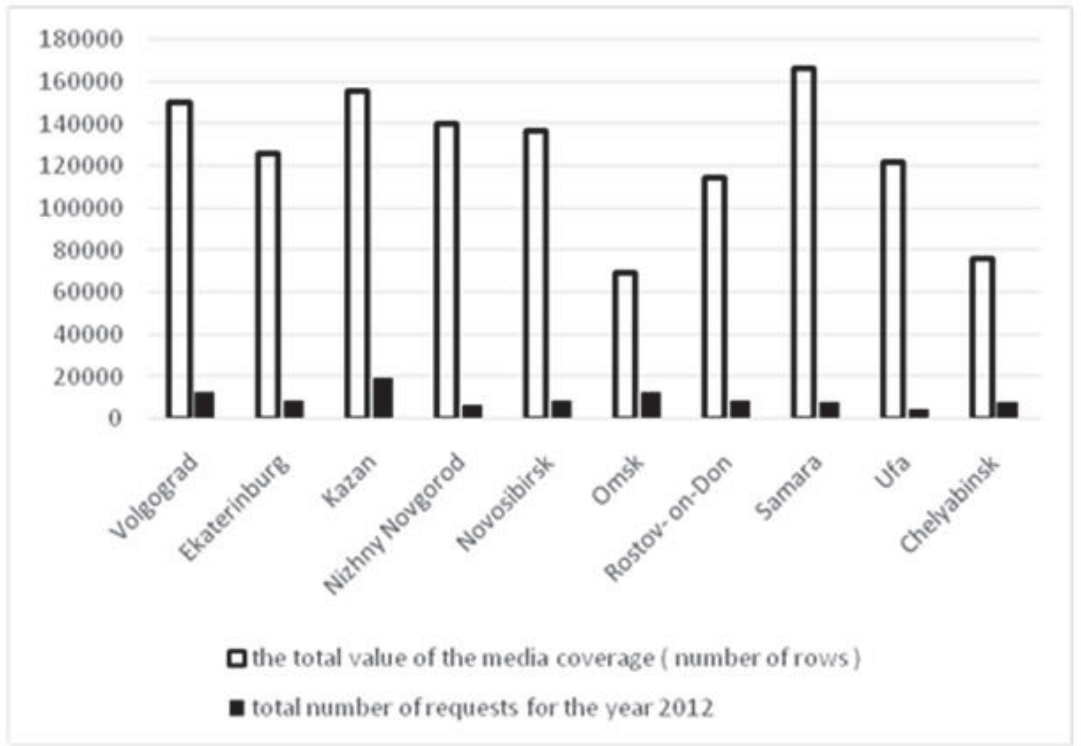

Fig. 1 Ratio of total value of indicators of illumination and quantity of search queries on the cities million plus cities of Russia

The above chart shows a ratio between amount of information which is covered in federal newspapers and the general with amount of inquiries in the search engine Yandex.ru on any subjects. The smallest difference between the studied two criteria is revealed in the cities of Omsk and Chelyabinsk, in them information in mass media, especially on problems of the social sphere, economy and culture is least of all lit. The amount of inquiries on these cities is also small, however the difference is significantly less, than for example in Samara, Volgograd and Kazan. These cities are widely covered in newspapers of federal value, but amount of inquiries in comparison with amount of information in mass media are very small.

\section{Conclusion}

When carrying out comparison of indicators in all 10 million-plus cities on the allocated aspects it is impossible to allocate the city - the leader in all indicators. In most cases Volgograd and Kazan, sometimes and Samara, have one of the highest rates. The special attention is paid to the city of Kazan as to the city with rough rates of development in many spheres (political, economic, sports, cultural).

On the basis of the obtained data on information illumination of the cities in the central press it is possible to draw a conclusion on need of carrying out more purposeful work for capital cities in the field of ensuring safety in them for minimization of processes of distribution of information on various incidents (especially in Ufa, Volgograd, Omsk, Yekaterinburg) as it is adversely reflected in appeal and reputation of the cities in general. For the authorities of Yekaterinburg, Nizhny Novgorod, Kazan an important task is maintenance of the status of the cities with developed economy. Activization of work on their competent lighting in this sphere is for this purpose necessary.

In Novosibirsk, Yekaterinburg, Nizhny Novgorod it is necessary to pay close attention to aspect of culture which doesn't find due reflection in the press. Perhaps, creation of special events (carrying out actions, exhibitions, concerts) which will draw attention of members of the media and residents will be effective steps. A problem subject practically for each city (except for Kazan) is low illumination of a religious component. The authorities of the cities need to carry out the analysis of level of interest of inhabitants religious subject and if necessary to give it attention in mass media more.

Unfortunately, the social aspect of a municipal government doesn't find due reflection in capital cities, it emphasizes their insolvency and a low social orientation in the development. Therefore as the recommendation it would be desirable to advise local administrations to speed up work in the social sphere. These actions could cause interest as from the press, and directly from inhabitants and respectively to increase quality of life in this territory.

The carried-out content analysis allowed to trace not only the level of information illumination of various subjects in mass media, but also to analyse activity of the carried-out work in the field of a municipal government in the Russian capitals for correction of work of their separate services and committees that in turn will positively be reflected in appeal of the territory in general. 


\section{References}

Batista e Silva J., da GraçaSaraiva M., Loupa Ramos I., Bernardo F.Improving Visual Attractiveness to Enhance City-River Integration-A Methodological Approach for Ongoing Evaluation //Planning Practice and Research (28), 2013. pp. 163-185.

Blanc-Brude F., Cookson G., Piesse J., Strange R. The FDI location decision: Distance and the effects of spatial dependence // International Business Review (23), 2014. pp. 797-810.

Razumovskaya, E.M., Mishakin, T.S., Popov, M.L., Kucevol, N.G. Medical services during the XXVII world summer universiade 2013 in Kazan. Mediterranean Journal of Social Sciences, Volume 5, Issue 18 SPEC. ISSUE, 2014, Pages 17-20.

Bagautdinova, N.G., Fatkhiev, A.M., Novenkova, A.Z., Safiullina, A.M. (2014). The stages of the innovation process. Recent Trends in Social and Behaviour Sciences - Proceedings of the 2nd International Congress on Interdisciplinary Behavior and Social Sciences 2013, ICIBSoS 2013, Pages 315-318.

HeritageZ.a, Green G.bEuropean national healthy city networks: The impact of an elite epistemic community //Journal of Urban Health (90), 2013. pp. 154-166.

Hu R., Blakely E.J., Zhou Y. Benchmarking the Competitiveness of Australian Global Cities: Sydney and Melbourne in the Global Context // Urban Policy and Research (31), 2013. pp. 435-452.

Kashnitsky I. Migration of youths in Russia: Impact on sex-age structures // Mediterranean Journal of Social Sciences (4), 2013. pp. 358-365.

Min K.S., Martin D., Jung J.M.Designing advertising campaigns for destinations with mixed images: Using visitor campaign goal messages to motivate visitors // Journal of Business Research (66), 2013. pp. 759-764.

Safiullina, A.M., Odintsova, J.L., Zhilina, N.N.,Shamsutdinova, M.R. The main participants of innovation climate development (on the example of the Russian federation). Mediterranean Journal of Social Sciences, 5 (18 SPEC. ISSUE), pp. 197-202

Montanari F., Scapolan A., Codeluppi E. Identity and social media in an art festival // Tourism Social Science Series (18), 2013. pp. 207225.

Razumovskaya, E.M. , Kutsevol, N., Popov, M., Mishakin, T., Leto, L., Tsalikova, V. The effectiveness of management practice in the market of socially important services, Asian Social Science, Volume 10, 28 September 2014, Pages 118-122

Rakhmangulov A.N., Kopylova O.A.Assessment of socio-economic potential of regions for placement of the logistic infrastructure objects // Economy of Region (2), 2014. pp. 254-263.

Robinson S.The Active Citizen's Information Media Repertoire: An Exploration of Community News Habits During the Digital Age // Mass Communication and Society (17), 2014. pp. 509-530.

Sepe M., Pitt M. Improving liveability and attractiveness by preserving place identity in emblematic thoroughfares: A method and a case study // Urban Design International (18), 2013. pp. 229-249. 